\title{
Relation of Patients Living Without a Partner or Spouse to Being Physical Active after Acute Coronary Syndromes (From the PULSE Accelerometry Substudy)
}

\author{
Philip Green, MDa, Jonathan D. Newman, MD, MPH ${ }^{\mathrm{a}}$, Jonathan A. Shaffer, $\mathrm{PhD}^{\mathrm{b}}$, Karina W. \\ Davidson, PhD $^{\mathrm{b}}$, Mathew S. Maurer, MD $^{\mathrm{a}}$, and Joseph E. Schwartz, PhD ${ }^{\mathrm{b}, \mathrm{c}}$ \\ aDivisions of Cardiology and Department of Medicine, Columbia University Medical Center, New \\ York, NY \\ ${ }^{\mathrm{b}}$ Center for Behavioral Cardiovascular Health, Department of Medicine, Columbia University \\ Medical Center, New York, NY \\ 'Department of Psychiatry and Behavioral Science, Stony Brook University, Stony Brook, NY.
}

\section{Abstract}

Living alone is associated with adverse outcomes after an acute coronary syndrome (ACS). One potential mediator of the relationship between partner status and outcomes after an ACS is physical activity. To evaluate the association of partner status with physical activity after an ACS we analyzed data from 107 participants enrolled in the Prescription Use, Lifestyle, and Stress Evaluation Study, a prospective observational study of post-ACS patients. Accelerometers were employed to measure physical activity following hospital discharge. The primary outcome measure was maximum 10 hours of daytime activity one month after discharge. One month after discharge from an ACS hospitalization, participants without a partner or spouse exhibited 24.4\% lower daytime activity than those with a partner or spouse $(\mathrm{p}=0.003)$. After controlling for age, gender, body mass index, Charlson comorbidity index, and traditional psychosocial and clinical cardiovascular correlates of post-ACS physical activity, partner status remained an independent predictor of post-ACS physical activity $20.5 \%$ lower daytime activity among those without partner or spouse, $\mathrm{p}=0.008$ ). In conclusion, in this study of accelerometer-measured physical activity after an ACS hospitalization, those without a partner or spouse exhibit significantly less physical activity than those with a partner or spouse one month after discharge from the hospital. Low physical activity may be an important mediator of the prognosis associated with partner status after an ACS.

\section{Keywords}

Partner status; physical activity; acute coronary syndrome; accelerometer

\footnotetext{
(C) 2013 Excerpta Medica, Inc. All rights reserved.

Corresponding author: Philip Green, MD Columbia University Medical Center 622 West $168^{\text {th }}$ Street, PH 10-203 New York, NY 10032 pg2336@columbia.edu Tel:212-342-3617 Fax:212-342-5375.

Publisher's Disclaimer: This is a PDF file of an unedited manuscript that has been accepted for publication. As a service to our customers we are providing this early version of the manuscript. The manuscript will undergo copyediting, typesetting, and review of the resulting proof before it is published in its final citable form. Please note that during the production process errors may be discovered which could affect the content, and all legal disclaimers that apply to the journal pertain.

None of the authors have any conflicts of interest to disclose.
} 


\section{INTRODUCTION}

Living alone is an important risk factor for adverse events after acute coronary syndromes (ACS). However, the mechanism underlying this relationship is not well understood. One proposed mediator of the relationship between living alone and post-ACS adverse events is physical activity. Prior studies have shown that a low level of physical activity is associated with increased risk of recurrent cardiovascular events and increased risk of mortality after myocardial infarction (MI). ${ }^{1-5}$ However, previous studies that have examined the relationship between post-ACS physical activity and prognosis, have relied on self-reported physical activity, ${ }^{5}$ which is limited by recall bias and correlates only moderately well with objective assessments of physical activity. ${ }^{6}$ In contrast, accelerometers provide a more accurate representation of day-to-day physical activity and better predict adverse events. ${ }^{7}$ Therefore, to determine if physical activity is associated with partner status, a preliminary step towards determining if physical activity mediates the association of living alone with increased risk of adverse post-ACS events, we evaluated the relationship between partner status and post-ACS physical activity as measured by continuously worn accelerometers using data from the Prescription Use, Lifestyle, and Stress Evaluation (PULSE) Study.

\section{METHODS}

Participants were hospitalized patients with an ACS enrolled in PULSE, a prospective cohort study of the prognostic risk conferred by depression at the time of an ACS. Five hundred patients with unstable angina or acute ST or non-ST segment elevation MI at Columbia University Medical Center were recruited between February 1, 2009 and June 30, 2010, within 1 week of their hospitalization. Participants returned for a follow-up visit one month later. Excluded from analyses were 225 participants who were not approached or did not agree to wear the accelerometer; 105 participants who did not return the accelerometer; and 61 participants who were non-adherent with accelerometer use during the study. Two patients undergoing coronary artery bypass surgery and balloon aortic valvuloplasty were also excluded, as the invasiveness of these procedures may confound the association between any predictor and level of post-ACS physical activity. The current analysis therefore includes 107 PULSE participants treated with percutaneous coronary intervention or medical therapy for ACS during the index hospitalization. The Institutional Review Board of Columbia University Medical Center approved this study, and all participants provided informed consent.

Participants were provided with an Actical ${ }^{\circledR}$ (Philips - Respironics, Inc, Bend, Oregon) accelerometer device prior to discharge or were mailed the device following discharge from their ACS hospitalization. They were instructed to wear the device on their non-dominant wrist continuously (including during sleep) and to return the device at the 1-month postdischarge follow-up visit. The Actical ${ }^{\circledR}$ is a small, wristwatch-like, omni-directional accelerometer that provides real-time ambulatory monitoring and quantification of activity levels. Data were monitored continuously and recorded in 1-minute epochs, resulting in an activity count for each minute of the day. To be included in the current analyses, participants were required to have worn the device for at least 5 days within 45 days of their discharge from the hospital. Accelerometer non-adherence, evaluated for each day, was defined as more than 4 hours of total inactivity recorded by the device during daytime hours (6:00 AM to 10:00 PM). Data for non-adherent days were excluded from the analysis. The following measures of activity between 6:00 AM and 10:00 PM were then derived. M10h, a measure of a participant's overall daytime activity, is the total activity count of the most active 10 hours in the day (need not be 10 consecutive hours). ${ }^{7,8}$ This measures has previously been employed in a study of patients with chronic heart failure to summarize overall activity. 7,9 
At baseline, a trained research assistant interviewed participants. Age, gender, ethnicity (Hispanic versus non-Hispanic), race (White versus Black versus Other), and partner status (presence or absence of partner or spouse) were determined by patient self-report. Systematic medical chart extraction was performed to ascertain prior history of cardiovascular diseases (angina, MI, stroke, peripheral arterial disease, heart failure, and New York Heart Association heart failure class); cardiovascular procedures (percutaneous coronary angioplasty [PTCA] and coronary artery bypass grafting); and history of other chronic medical conditions (respiratory diseases, liver diseases, rheumatologic diseases, and stomach ulcers). The Global Registry of Acute Coronary Events (GRACE) risk score was used to calculate 6 -month post-ACS mortality risk, ${ }^{10}$ and the Charlson comorbidity index was used to assess severity of medical comorbidities. ${ }^{11}$ Left ventricular ejection fraction was assessed by echocardiography, ventriculography, or nuclear stress testing. Acute coronary syndrome type (unstable angina, ST-segment MI, non-ST-segment MI) was determined from chart review by study cardiologists according to standard criteria. ${ }^{12}$ Treatment strategy (PTCA or medical therapy) and length of hospitalization for index ACS event were obtained by chart review.

Participants' symptoms of depression were ascertained at baseline based on their selfreported responses to the 21 -item Beck Depression Inventory. ${ }^{13}$ Symptoms of anxiety were assessed by participants' self-reported responses to the anxiety subscale of the Hospital Anxiety and Depression Scale (HADS-A). ${ }^{14}$ Anergia (lack of energy) was assessed using a validated anergia assessment tool. ${ }^{9}, 15,16$ Perceived social support was assessed using the ENRICH-D Social Support Index based on the responses to 7 items shown to be predictive of outcomes in heart disease and scored according to standard methods. ${ }^{17}$ To be categorized as having low perceived social support, participants had to have either: A) a score of 3 or lower on any two items in combination with a total score of 18 or lower or B) a score of 2 or lower on any two items, as has been previously published. ${ }^{17}$

Demographic, psychosocial, and clinical factors are presented as proportions, means (SD), or medians (interquartile ranges). The primary outcome variable was estimated daytime activity level (M10h) on the $30^{\text {th }}$ day after discharge from ACS hospitalization derived from a multilevel growth curve model designed to leverage the accelerometer data from the entire post-discharge period and account for missing data and outliers. The distribution of M10h was positively skewed; preliminary analyses indicated that the optimal Box-Cox transformation was the natural log transformation, and thus this transformation was used for all analyses. Multilevel growth curve models were used to model within-person trajectories of daytime physical activity during the first 45 days post-discharge. Preliminary analyses demonstrated that the optimal model specification included linear and quadratic terms for post-discharge day (time), with these terms and the intercept treated as random effects. With appropriate scaling of time, the within-person intercepts represent the estimated activity level on the $30^{\text {th }}$ day post-discharge. Using this growth curve model as a base, partner status and all other covariates were individually added to the model to assess their bivariate associations with estimated physical activity (M10h) on Day 30. Subtracting 1 from the exponentiated parameter estimate for each covariate (and its 95\% confidence limits) yielded the percent difference in activity associated with a 1-unit difference in the covariate. Subsequent models were estimated to assess the independent association of partner status with Day 30 activity after adjusting for demographic, psychosocial and clinical predictors. As age was the most powerful predictor of activity in bivariate analyses, the relationship of all other covariates with post-ACS activity was evaluated in age-adjusted models. Those covariates that demonstrated an age-adjusted association with activity at a significance level of $\mathrm{p}<0.15$ were included in a fully-adjusted multivariable model. To confirm that the inclusion of participants with a small number of accelerometer days did not have an undue influence of the results, analyses were repeated after restricting the dataset to participants 
with 15 or more days of accelerometer wear time $(n=72)$. All analyses were performed in SAS 9.2 (Cary, North Carolina). A p-value of less than or equal to 0.05 was considered statistically significant.

\section{RESULTS}

Demographic, psychosocial, and clinical characteristics of participants are reported in Table 1. The median accelerometer wear time for participants was 23 days (interquartile range 10-33). The median age was 63 years (interquartile range 55-71), and there were more male $(65 \%)$ than female participants. Participants of Hispanic ethnicity constitute $36 \%$ of the cohort, and $20 \%$ were Black. Overall, $57 \%$ of ACS events were unstable angina; $25 \%$ were non-ST elevation MI; and 18\% were ST elevation MI. The majority of participants (77\%) were treated with PTCA during hospitalization for their index ACS event, and the median length of index hospitalization was 3 days (interquartile range 2-5). A majority of participants had a history of chronic anginal symptoms (57\%), while relatively few participants had a history of symptomatic congestive heart failure (5\% with New York Heart Association class III or IV symptoms). The prevalence of prior MI was $28 \%$. The median Beck Depression Inventory score was 9 (interquartile range 4-13), and 37\% of participants met criteria for the syndrome of anergia (low energy). The majority of participants reported not having a partner or spouse (58\%).

Those living without a partner or spouse were $24 \%$ less active on Day 30 after discharge for an ACS than those living with a partner or spouse $(\mathrm{p}=0.003)$. Patients with anergia (low energy) were $20 \%$ less active than patients without anergia. Patients receiving PTCA during the index hospitalization exhibited $26 \%$ higher post-ACS physical activity level compared to patients who did not receive PTCA. Statistically significant clinical predictors of lower levels of physical activity included GRACE risk score (6\% decrease in activity per 10-point increase in GRACE risk score), history of stroke (38\% decreased activity in patients with a history of stroke), and length of index hospitalization ( $6 \%$ decreased activity per day of hospitalization). Older age and higher Charlson comorbidity scores were also associated with lower levels of physical activity. Low perceived social support as estimated by the ENRICH-D Social Support Index was not associated with post-ACS activity ( $\mathrm{p}=0.84)$. The unadjusted effects of demographic, clinical, and psychosocial factors on Day 30 physical activity after an ACS are presented in Table 2.

Partner status remained a significant predictor of post-ACS activity after adjusting for age, gender, BMI, Charlson comorbidity score, Beck Depression Inventory score, the presence of anergia (low energy), history of stroke, history of peripheral arterial disease, treatment with PTCA during ACS hospitalization, and length of index hospitalization (Table 3). In the fully adjusted model, patients without a partner or spouse were $20.5 \%$ less active than those living with a partner or spouse $(\mathrm{p}=0.008)$. Age and length of index hospitalization were also inversely associated with post-ACS activity after multivariate adjustment (Table 3 ). Results were similar after exclusion of 35 participants with less than 15 days of accelerometer wear time (data not presented).

\section{DISCUSSION}

We examined if partner status was associated with accelerometer-measured physical activity in a post-ACS population and found that living without a partner or spouse was independently associated with lower physical activity after an ACS compared to living with a partner or spouse. Specifically, estimated physical activity on Day 30 following discharge for an ACS hospitalization was $20 \%$ lower for patients without a partner or spouse than for married patients and/or those living with a partner, even when controlling for numerous 
important covariates. This analysis suggests that inactivity may be an important mediator of the risk associated with living without a partner or spouse after ACS, and could be a point of intervention for patients without partners, by clinicians and by future randomized controlled trials.

Lack of social support and its impact on outcomes in cardiovascular disease has been studied using several partially overlapping constructs without a clear consensus on the best way to measure social support in the research setting. ${ }^{18}$ Although low social support, living alone, and partner status are each related to the broader construct of social support, and have each been shown to predict outcomes in cardiovascular disease, these constructs are not synonymous. In the Multicenter Diltiazem Postinfarction Trial individuals classified as living alone after MI have a 4-fold increased risk of death compared to those with higher levels of social support. ${ }^{19}$ Norekvål confirmed these findings in a cohort of women post MI. ${ }^{20}$ However, Schmaltz reported that living alone was associated with increased mortality among men, but not women. ${ }^{21}$ In an analysis of the large GUSTO-III the crude association between living alone and 30-day or 1-year mortality after ST-elevation MI was no longer statistically significant after adjustment for other factors. ${ }^{22}$ Similarly, an analysis of the PREMIER Registry showed a crude association between living alone and increased mortality 4 years after MI. ${ }^{23}$ However, the association was no longer significant after adjustment for other patient and treatment characteristics including. ${ }^{23}$ Finally, data from the REACH Registry showed an increased risk of death at 4 years among those living alone. ${ }^{24}$ However, a significant interaction between age group and living alone was found such that living alone and mortality was not significant among participants older that 80 years of age. $^{24}$

If indeed partner status, and implicitly social support, are related to outcomes after ACS, it is important to understand how they impact physical activity and functional status. In a study designed to evaluate the impact of social support on physical function and mental health after coronary artery bypass surgery, Barry and colleagues demonstrated that among adults who received bypass ( $\mathrm{N}=1164,16 \%$ ACS) while overall survey-assessed physical function improved after bypass surgery, social support did not predict physical function. ${ }^{25} \mathrm{In}$ contrast, Pasquali and colleagues found that being married was independently associated with increased self-reported physical function after coronary revascularization with bypass surgery or percutaneous coronary angioplasty $(\mathrm{N}=730,80 \%$ acute $\mathrm{MI}){ }^{26}$ A meta-analysis performed by Molloy and colleagues suggested that patients with coronary heart disease who are married or partnered were 1.5-2.0 times more likely to attend the cardiac rehabilitation compared to patients who were not married or partnered. ${ }^{27}$ Our study is the first to demonstrate an association between objectively-measured physical activity using accelerometers and partner status after ACS.

Our study is not the first to employ accelerometers to monitor activity after ACS. Reid and colleagues measured leisure time physical activity at 2, 6 and 12 months after an ACS $(n=782)$. They found that gender (men were more active than women; $\mathrm{P}<0.001)$, chronic heart failure (those without heart failure were more active; $\mathrm{P}<0.01$ ), diabetes (those without diabetes were more active; $\mathrm{P}<0.05$ ), and pre-ACS level of physical activity (those active before hospitalization were more active after; $\mathrm{P}<0.001$ ) predicted activity level after an ACS. ${ }^{28}$ However, they did not examine psychosocial predictors of activity such as depressed mood, anxiety, or social support. Savage and colleagues measured activity-related energy expenditure using accelerometers in 15 obese adults at baseline and then 4 months after ACS. ${ }^{29}$ They demonstrated a linear relationship between increase in energy expenditure and weight loss among those who participated in high caloric exercise training. Our study is the first to employ continuous accelerometry-based activity monitoring after an ACS and to consider both psychosocial and clinical cardiovascular predictors. 
It must be noted that, in contrast to the significant association between partner status and post-ACS physical activity, low perceived social support as assessed by the ENRICH-D Social Support Index was not associated with post-ACS activity. The reasons for the discordance are unknown, however, others have reported similar discrepancies. In 271 adults undergoing PTCA, Vaglio found that the single question "Are you currently married or living with a partner?" was only weakly correlated with the overall ENRICH-D Social Support Index score $(\mathrm{r}=0.38) .{ }^{30}$ This suggests that partner status and perceived social support do not completely overlap, which likely accounts for the discrepant results in this study. Further studies will be needed to identify the mechanism behind the relationship between activity after an ACS and partner status.

These results should be interpreted in the context of several limitations. First, this is a small, single-center study in an urban academic medical center, which may limit the generalizability of its findings. As the majority of participants in this analysis presented with unstable angina, extrapolation of our findings to patients with MI may be particularly limited. Second, there are methodological concerns related to characterization of the index ACS hospitalization. For instance, we did not collect data on acute inpatient illnesses concomitant with index hospitalization, nor did we examine the receipt of inpatient physical therapy or cardiac rehabilitation on discharge, which may confound the observed predictors of post-ACS activity. Future studies will be needed to evaluate the impact of those factors and others on activity after ACS. Third, to be included in this analysis, we required that a participant have at least 5 days of adherence with accelerometer recording. As we analyzed predicted estimates and not actual measures of Day 30 activity, our ability to detect associations depends on the precision of the estimates. Sensitivity analysis to address this limitation was performed by repeating the analyses after excluding those participants with only a few days of wear time. Lastly, future research should more closely examine the interrelations of social support, living, and partner status with respect to cardiovascular disease outcomes.

\section{Acknowledgments}

Grant support: This work was supported by grants HL-088117, HL-098037, and HL-084034 from the National Heart, Lung, and Blood Institute, and by Grant Number UL1 RR024156 from the National Center for Research Resources (NCRR), a component of the National Institutes of Health (NIH) and NIH Roadmap for Medical Research. Dr. Shaffer is supported by grant number 12CRP8870004 from the American Heart Association. Its contents are solely the responsibility of the authors and do not necessarily represent the official view of NCRR or $\mathrm{NIH}$.

\section{References}

1. Morris JN, Everitt MG, Pollard R, Chave SP, Semmence AM. Vigorous exercise in leisure-time: Protection against coronary heart disease. Lancet. 1980; 2:1207-1210. [PubMed: 6108391]

2. Paffenbarger RS Jr. Hyde RT, Wing AL, Hsieh CC. Physical activity, all-cause mortality, and longevity of college alumni. New Eng J Med. 1986; 314:605-613. [PubMed: 3945246]

3. Smith SC Jr. Allen J, Blair SN, Bonow RO, Brass LM, Fonarow GC, Grundy SM, Hiratzka L, Jones D, Krumholz HM, Mosca L, Pasternak RC, Pearson T, Pfeffer MA, Taubert KA. Aha/acc guidelines for secondary prevention for patients with coronary and other atherosclerotic vascular disease: 2006 update: Endorsed by the national heart, lung, and blood institute. Circulation. 2006; 113:2363-2372. [PubMed: 16702489]

4. Thompson PD, Buchner D, Pina IL, Balady GJ, Williams MA, Marcus BH, Berra K, Blair SN, Costa F, Franklin B, Fletcher GF, Gordon NF, Pate RR, Rodriguez BL, Yancey AK, Wenger NK. Exercise and physical activity in the prevention and treatment of atherosclerotic cardiovascular disease: A statement from the council on clinical cardiology (subcommittee on exercise, rehabilitation, and prevention) and the council on nutrition, physical activity, and metabolism (subcommittee on physical activity). Circulation. 2003; 107:3109-3116. [PubMed: 12821592] 
5. Eaton CB, Medalie JH, Flocke SA, Zyzanski SJ, Yaari S, Goldbourt U. Self-reported physical activity predicts long-term coronary heart disease and all-cause mortalities. Twenty-one-year follow-up of the Israeli ischemic heart disease study. Arch Fam Med. 1995; 4:323-329. [PubMed: 7711918]

6. Aadahl M, Kjaer M, Kristensen JH, Mollerup B, Jorgensen T. Self-reported physical activity compared with maximal oxygen uptake in adults. Eur J Cardiovasc Prev Rehabil. 2007; 14:422428. [PubMed: 17568243]

7. Howell J, Strong BM, Weisenberg J, Kakade A, Gao Q, Cuddihy P, Delisle S, Kachnowski S, Maurer MS. Maximum daily 6 minutes of activity: An index of functional capacity derived from actigraphy and its application to older adults with heart failure. J Am Geriatr Soc. 2010; 58(5):9316. [PubMed: 20374397]

8. Witting W, Kwa IH, Eikelenboom P, Mirmiran M, Swaab DF. Alterations in the circadian restactivity rhythm in aging and alzheimer's disease. Biol Psych. 1990; 27:563-572.

9. Maurer MS, Cuddihy P, Weisenberg J, Delisle S, Strong BM, Gao Q, Kachnowski S, Howell J. The prevalence and impact of anergia (lack of energy) in subjects with heart failure and its associations with actigraphy. J Card Fail. 2009; 15:145-151. [PubMed: 19254674]

10. Granger CB, Goldberg RJ, Dabbous O, Pieper KS, Eagle KA, Cannon CP, Van De Werf F, Avezum A, Goodman SG, Flather MD, Fox KA. Predictors of hospital mortality in the global registry of acute coronary events. Arch Intern Med. 2003; 163:2345-2353. [PubMed: 14581255]

11. Charlson M, Szatrowski TP, Peterson J, Gold J. Validation of a combined comorbidity index. J of Clin Epid. 1994; 47:1245-1251.

12. Cannon CP, Battler A, Brindis RG, Cox JL, Ellis SG, Every NR, Flaherty JT, Harrington RA, Krumholz HM, Simoons ML, Van De Werf FJJ, Weintraub WS, Mitchell KR, Morrisson SL, Anderson HV, Cannom DS, Chitwood WR Jr. Cigarroa JE, Collins-Nakai RL, Gibbons RJ, Grover FL, Heidenreich PA, Khandheria BK, Knoebel SB, Krumholz HL, Malenka DJ, Mark DB, McKay CR, Passamani ER, Radford MJ, Riner RN, Schwartz JB, Shaw RE, Shemin RJ, Van Fossen DB, Verrier ED, Watkins MW, Phoubandith DR, Furnelli T. American College of Cardiology key data elements and definitions for measuring the clinical management and outcomes of patients with acute coronary syndromes: A report of the American College of Cardiology Task Force on Clinical Data Standards (Acute Coronary Syndromes Writing Committee) endorsed by the American Association of Cardiovascular and Pulmonary Rehabilitation, American College of Emergency Physicians, American Heart Association, Cardiac Society of Australia \& New Zealand, National Heart Foundation of Australia, Society for Cardiac Angiography and Interventions, and the Taiwan Society of Cardiology. J Am Coll Cardiol. 2001; 38:2114-2130. [PubMed: 11738323]

13. Beck AT, Ward CH, Mendelson M, Mock J, Erbaugh J. An inventory for measuring depression. Arch Gen Psych. 1961; 4:561-571.

14. Zigmond AS, Snaith RP. The hospital anxiety and depression scale. Acta Psych Scand. 1983; 67:361-370.

15. Cheng H, Gurland BJ, Maurer MS. Self-reported lack of energy (anergia) among elders in a multiethnic community. J Ger Bio Sci Med Sci. 2008; 63:707-714.

16. Shaffer JA, Davidson KW, Schwartz JE, Shimbo D, Newman JD, Gurland BJ, Maurer MS. Prevalence and characteristics of anergia (lack of energy) in patients with acute coronary syndrome. Am J Cardiol. 2012

17. Enhancing recovery in coronary heart disease patients (enrichd): Study design and methods. The enriched investigators. Am Heart J. 2000; 139:1-9. [PubMed: 10618555]

18. Bucholz EM, Krumholz HM. Loneliness and living alone: What are we really measuring? Arch Intern Med. 2012; 172:1084-1085. [PubMed: 22710997]

19. Case RB, Moss AJ, Case N, McDermott M, Eberly S. Living alone after myocardial infarctionimpact on prognosis. JAMA. 1992; 267:515-519. [PubMed: 1729573]

20. Norekval TM, Fridlund B, Rokne B, Segadal L, Wentzel-Larsen T, Nordrehaug JE. Patientreported outcomes as predictors of 10-year survival in women after acute myocardial infarction. Health Qual Life Outcomes. 2010; 8:140. [PubMed: 21108810] 
21. Schmaltz HN, Southern D, Ghali WA, Jelinski SE, Parsons GA, King KM, Maxwell CJ. Living alone, patient sex and mortality after acute myocardial infarction. J Gen Intern Med. 2007; 22:572-578. [PubMed: 17443363]

22. O'Shea JC, Wilcox RG, Skene AM, Stebbins AL, Granger CB, Armstrong PW, Bode C, Ardissino D, Emanuelsson H, Aylward PE, White HD, Sadowski Z, Topol EJ, Califf RM, Ohman EM. Comparison of outcomes of patients with myocardial infarction when living alone versus those not living alone. Am J Cardiol. 2002; 90:1374-1377. [PubMed: 12480048]

23. Bucholz EM, Rathore SS, Gosch K, Schoenfeld A, Jones PG, Buchanan DM, Spertus JA, Krumholz HM. Effect of living alone on patient outcomes after hospitalization for acute myocardial infarction. Am J Cardiol. 2011; 108:943-948. [PubMed: 21798499]

24. Udell JA, Steg PG, Scirica BM, Smith SC Jr, Ohman EM, Eagle KA, Goto S, Cho JI, Bhatt DL. Living alone and cardiovascular risk in outpatients at risk of or with atherothrombosis. Arch Intern Med. 2012; 172:1086-1095. [PubMed: 22711020]

25. Barry LC, Kasl SV, Lichtman J, Vaccarino V, Krumholz HM. Social support and change in healthrelated quality of life 6 months after coronary artery bypass grafting. J Psychosom Res. 2006; 60:185-193. [PubMed: 16439272]

26. Pasquali SK, Alexander KP, Coombs LP, Lytle BL, Peterson ED. Effect of cardiac rehabilitation on functional outcomes after coronary revascularization. Am Heart J. 2003; 145:445-451. [PubMed: 12660667]

27. Molloy GJ, Hamer M, Randall G, Chida Y. Marital status and cardiac rehabilitation attendance: A meta-analysis. Eur J Cardiovasc Prev Rehabil. 2008; 15:557-561. [PubMed: 18800004]

28. Reid RD, Morrin LI, Pipe AL, Dafoe WA, Higginson LAJ, Wielgosz AT, McDonald PW, Plotnikoff RC, Courneya KS, Oldridge NB, Beaton LJ, Papadakis S, D’ Angelo MES, Tulloch HE, Blanchard CM. Determinants of physical activity after hospitalization for coronary artery disease: The tracking exercise after cardiac hospitalization (teach) study. Eur J Cardiovasc Prev Rehab. 2006; 13:529-537.

29. Savage PD, Brochu M, Poehlman ET, Ades PA. Reduction in obesity and coronary risk factors after high caloric exercise training in overweight coronary patients. Am Heart J. 2003; 146:317323. [PubMed: 12891202]

30. Vaglio J Jr. Conard M, Poston WS, O'Keefe J, Haddock CK, House J, Spertus JA. Testing the performance of the enrichd social support instrument in cardiac patients. Health Qual Life Outcomes. 2004; 2:24. [PubMed: 15142277] 


\section{Tables 1}

Demographic, psychosocial, and clinical characteristics of 107 participants with acute coronary syndromes and accelerometer-assessed physical activity

\begin{tabular}{|c|c|}
\hline Age (years), median (IQR) & $63(55-71)$ \\
\hline Men & $70(65 \%)$ \\
\hline Body mass index $\left(\mathrm{kg} / \mathrm{m}^{2}\right)$, median $(\mathrm{IQR})$ & $28.2(25.7-31.2)$ \\
\hline Hispanic & $39(36 \%)$ \\
\hline Black & $21(20 \%)$ \\
\hline Charlson comorbidity index, median & (IQR) $1(0-2)$ \\
\hline Chronic lung disease & $12(11 \%)$ \\
\hline \multicolumn{2}{|l|}{ Acute coronary syndrome } \\
\hline Unstable angina pectoris & $61(57 \%)$ \\
\hline Non ST elevation myocardial infarction & $27(25 \%)$ \\
\hline ST elevation myocardial infarction & $19(18 \%)$ \\
\hline \multicolumn{2}{|l|}{ Characteristics of acute coronary syndrome hospitalization } \\
\hline Treated with percutaneous coronary angioplasty & $82(77 \%)$ \\
\hline Length of hospital stay (days), median (IQR) & $3(2-5)$ \\
\hline Grace risk score, median (IQR) & $65(84-106)$ \\
\hline Left ventricular ejection fraction (\%), median (IQR) & $53(45-58)$ \\
\hline Left ventricular ejection fraction $<40 \%$ & $9(8 \%)$ \\
\hline \multicolumn{2}{|l|}{ History of cardiovascular diseases and related procedures } \\
\hline Myocardial infarction & $30(28 \%)$ \\
\hline Percutaneous coronary angioplasty & $46(43 \%)$ \\
\hline Coronary artery bypass grafting & $16(15 \%)$ \\
\hline Stroke & $4(4 \%)$ \\
\hline Peripheral arterial disease & $5(5 \%)$ \\
\hline Congestive heart failure & $10(9 \%)$ \\
\hline New York Heart Association class III/IV & $5(5 \%)$ \\
\hline History of chronic angina pectoris & $61(57 \%)$ \\
\hline \multicolumn{2}{|l|}{ Psychosocial symptoms and social support } \\
\hline \multicolumn{2}{|l|}{ Partner status } \\
\hline Partner/spouse & $45(42 \%)$ \\
\hline No partner spouse & $62(58 \%)$ \\
\hline \multicolumn{2}{|l|}{ Depression symptom severity } \\
\hline Beck Depression Inventory, median (IQR) & $9(4-13)$ \\
\hline Anergia & $38(37 \%)$ \\
\hline HADS-A, median (IQR) & $3(1-6)$ \\
\hline Low perceived social support & $12(11 \%)$ \\
\hline
\end{tabular}

HADS-A -- anxiety subscale of the Hospital Anxiety and Depression Scale; IQR - interquartile range 
Table 2

Unadjusted associations of demographic, psychosocial, and clinical characteristics with estimated physical activity on Day 30 post-discharge for an ACS hospitalization

\begin{tabular}{|c|c|c|}
\hline & $\begin{array}{l}\% \text { difference in activity } \\
(95 \% \text { confidence limits })\end{array}$ & p-value \\
\hline Age, per 10-year increase & $-15 \%(-21,-9)$ & $<0.0001$ \\
\hline Men & $16 \%(-4,41)$ & 0.13 \\
\hline Body mass index $\left(\mathrm{kg} / \mathrm{m}^{2}\right)$ & $-1 \%(-3,1)$ & 0.26 \\
\hline Hispanic & $-9 \%(-24,11)$ & 0.36 \\
\hline Black & $-16 \%(-33,7)$ & 0.16 \\
\hline Charlson comorbidity index & $-8 \%(-12,-2)$ & 0.01 \\
\hline Chronic lung disease & $-16 \%(-37,12)$ & 0.24 \\
\hline \multicolumn{3}{|l|}{ Acute coronary syndrome } \\
\hline ST elevation myocardial infarction & (reference) & 0.59 \\
\hline Non ST elevation myocardial infarction & $-7 \%(-29,23)$ & \\
\hline Unstable angina & $-12 \%(-31,13)$ & \\
\hline \multicolumn{3}{|l|}{ Index acute coronary syndrome hospitalization } \\
\hline Treated with percutaneous coronary angioplasty & $26 \%(2,55)$ & 0.04 \\
\hline Length of hospital stay, days & $-6 \%(-8,-3)$ & $<0.0001$ \\
\hline Grace risk score, per 10-point increase & $-6 \%(-9,-3)$ & $<0.0001$ \\
\hline Left ventricular ejection fraction, per $10 \%$ increase & $-0.03 \%(-8,9)$ & 0.99 \\
\hline Left ventricular ejection fraction $<40 \%$ & $-2 \%(-29,36)$ & 0.92 \\
\hline \multicolumn{3}{|l|}{ History of cardiovascular diseases and related procedures } \\
\hline Myocardial infarction & $-13 \%(-29,6)$ & 0.17 \\
\hline Percutaneous coronary angioplasty & $4 \%(-13,26)$ & 0.66 \\
\hline Coronary artery bypass grafting & $-9 \%(-30,18)$ & 0.46 \\
\hline Stroke & $-38 \%(-62,-0.4)$ & 0.051 \\
\hline Peripheral arterial disease & $-33 \%(-57,4)$ & 0.07 \\
\hline Congestive heart failure & $-6 \%(-31,29)$ & 0.71 \\
\hline New York Heart Association class III/IV & $-2 \%(-48,19)$ & 0.26 \\
\hline History of chronic angina & $-4 \%(-21,15)$ & 0.65 \\
\hline \multicolumn{3}{|l|}{ Psychosocial symptoms and social support } \\
\hline Beck Depression Inventory (per 5-point increase) & $-5 \%(-10,1)$ & 0.12 \\
\hline Beck Depression Inventory $>10$ & $-9 \%(-24,10)$ & 0.32 \\
\hline Anergia & $-20 \%(-34,-3)$ & 0.03 \\
\hline HADS-A (per 1 point increase) & $1 \%(-2,4)$ & 0.43 \\
\hline No partner or spouse & $-24 \%(-37,-10)$ & 0.003 \\
\hline Low perceived social support & $-3 \%(-28,30)$ & 0.84 \\
\hline
\end{tabular}

HADS-A - anxiety subscale of the Hospital Anxiety and Depression Scale 
Table 3

Multivariable predictors of activity one month after discharge

\begin{tabular}{|c|c|c|c|c|c|c|}
\hline \multirow[b]{2}{*}{ Variable } & \multicolumn{2}{|c|}{ Model 1} & \multicolumn{2}{|c|}{ Model 2} & \multicolumn{2}{|c|}{ Model 3} \\
\hline & $\begin{array}{l}\text { \% difference } \\
\text { in activity }\end{array}$ & p value & $\begin{array}{l}\text { \% difference } \\
\text { in activity }\end{array}$ & p value & $\begin{array}{l}\text { \% difference } \\
\text { in activity }\end{array}$ & p value \\
\hline No spouse or partner & $-25 \%$ & 0.001 & $-26 \%$ & 0.0006 & $-20 \%$ & 0.008 \\
\hline Age (per 10 year increase) & $-15 \%$ & $<0.0001$ & $-15 \%<0.0001$ & $<0.0001$ & $-13 \%$ & 0.0003 \\
\hline Men & $-3 \%$ & 0.75 & $-4 \%$ & 0.71 & $-2 \%$ & 0.84 \\
\hline Body mass index & $-1 \%$ & 0.31 & $-1 \%$ & 0.40 & $-1 \%$ & 0.38 \\
\hline Charlson comorbidity index & $-5 \%$ & 0.08 & $-4 \%$ & 0.13 & $-3 \%$ & 0.29 \\
\hline Beck Depression Inventory Score (per 5 point increase) & & & $-1 \%$ & 0.79 & $0 \%$ & 0.90 \\
\hline Anergia & & & $-2 \%$ & 0.87 & $-9 \%$ & 0.35 \\
\hline History of stroke & & & & & $-13 \%$ & 0.53 \\
\hline History of peripheral arterial disease & & & & & $-5 \%$ & 0.82 \\
\hline $\begin{array}{l}\text { Treated with percutaneous coronary angioplasty during } \\
\text { index hospitalization }\end{array}$ & & & & & $3 \%$ & 0.82 \\
\hline Length of index ACS hospitalization & & & & & $-4 \%$ & 0.002 \\
\hline
\end{tabular}

Model 1 includes demographics, body mass index, and other Charlson comorbidity scale as covariates.

Model 2 adds other psychosocial factors to the covariates already included in Model 1.

Model 3 adds clinical cardiovascular factors to the covariates already included in Model 2.

ACS, acute coronary syndrome 